\title{
INTELECTUAIS CONTRA O PODER: A atualidade do ENGajamento POLÍtico-cultural de IgNazio Silone e Nicola Chiaromonte na direção de Tempo Presente'
}

\author{
Doris Nátia Cavallari² \\ FFLCH-USP \\ CAPES
}

RESUMO: Apresento algumas informações sobre a revista Tempo Presente: informazione e discussione, dirigida por Ignazio Silone e Nicola Chiaromonte, no período de 1956 a 1968. O estudo da revista foi objeto de minha pesquisa de pós-doutorado e se deteve no levantamento e análise dos textos, em particular aqueles produzidos por Silone e Chiaromonte, para verificar em que modo os artigos garantiram o sucesso da revista entre seus leitores, um grupo especial de intelectuais, pelo período de doze anos. Ao final, acrescento a tradução de um dos textos de Nicola Chiaromonte, crítico desconhecido no Brasil, no qual se pode sentir a sensibilidade e

1. Este trabalho apresenta resultado parcial de pesquisa de pós-doutorado realizado, com ônus Capes, junto à Università degli Studi “G. D’Annunzio” di Chieti-Pescara- Itália (entre setembro 2010-julho 2011).

2. Faculdade de Filosofia, Letras e Ciências Humanas - USP dorin@usp.br 
profundidade com que ele analisava as questões da literatura e do seu tempo presente.

PALAVRAS-CHAVE: Ignazio Silone, Nicola Chiaromonte, Tempo Presente, ideologia, intelectuais.

ABSTRACT: Presento alcune informazioni sulla rivista Tempo Presente: informazione e discussione, diretta da Ignazio Silone e Nicola Chiaromonte, nel periodo che va dal 1956 al 1968. Lo studio di questa rivista è stato oggetto della mia ricerca di post dottorato, dedicata soprattutto alla rilevazione e all'analisi dei testi, specialmente quelli scritti da Silone e Chiaromonte, allo scopo di verificare in che modo $i$ loro articoli hanno garantito il successo della rivista fra $i$ suoi lettori, un gruppo speciale di intellettuali, nel corso di dodici anni. Presento, inoltre, la traduzione di uno dei testi di Nicola Chiaromonte, critico non conosciuto in Brasile, nel quale si può cogliere la sensibilità e la profondità con le quali egli analizzava le questioni della letteratura e del suo tempo presente.

PAROLE CHIAVE: Ignazio Silone, Nicola Chiaromonte, Tempo Presente; ideologia, intellettuali.

ABSTRACT: Here I present some information on Tempo Presente: informazione e discussione journal, directed by Ignazio Silone and Nicola Chiaromonte, from 956 to 1968. The journal study was the object of my post doctorate research and its focus was on the survey and analyzes of texts, especially those produced by Silone and Chiaromonte, in order to verify how the articles have guaranteed the journal success for the readers, a special group of intellectual people, for twelve years. At the end, I add a translation of one of Nicola Chiaromonte's texts, an unknown reviewer in Brazil, in which it is possible to feel how sensitivity and deeply he analyzed literature issues and his present time.

KEYWORDS: Ignazio Silone; Nicola Chiaromonte; Tempo Presente; ideology; intellectual. 
"La libertà... è la possibilità di dubitare, la possibilità di sbagliare, la possibilità di cercare, di esperimentare, di dire di no a una qualsiasi autorità, letteraria artistica filosofica religiosa sociale, e anche politica."

Ignazio Silone

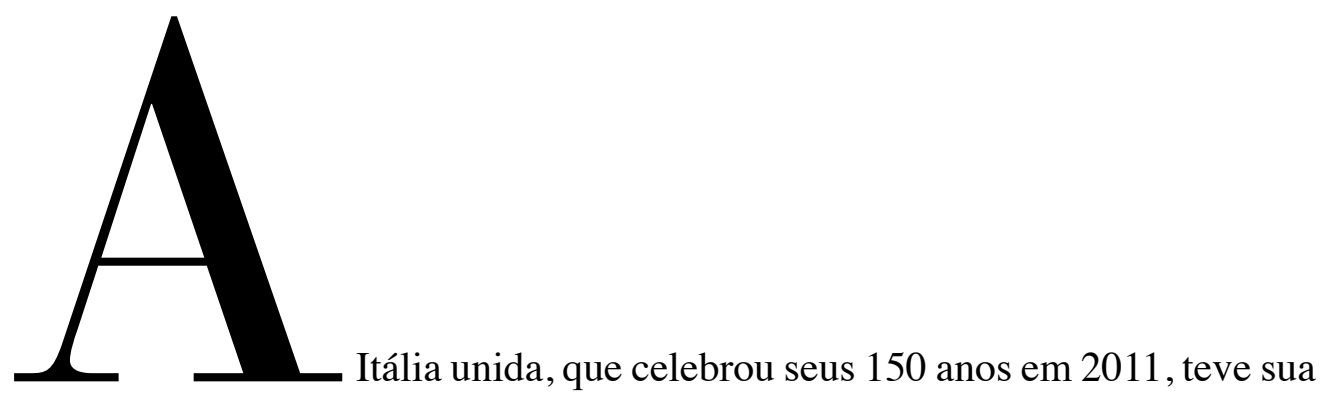
realidade político-social muitas vezes analisada por revistas de caráter políticocultural de grande importância, desde os primeiros anos do século XX. O país recém-unificado investiu na grande industrialização, provocando o nascimento de estratos sociais, como a rica burguesia moderna e o proletariado. Guiadas pelos marcantes ideais socialistas daquele período, as classes trabalhadoras começavam, então, a se organizar em associações sindicais. Para conter o crescimento de movimentos sociais populares, os governos promoveram "políticas de massas" que, aparentemente, privilegiavam a igualdade e os 
direitos civis, mas, na verdade, nada mais eram do que uma tentativa das classes dominantes de inibir as ações dos partidos proletários, em nome de uma "justiça igual para todos".

Tais inovações do novo século trouxeram consigo a exigência de meios de expressão mais modernos que alcançassem tanto as classes trabalhadoras quanto a intelectual, a qual vivia naquele momento a crise dos ideais românticos e das ideias positivistas que marcaram o final do século XIX. Nesse contexto, surgiram as revistas de crítica literária e política que gozavam de grande liberdade em relação aos meios acadêmicos consagrados. Além disso, como recorda Romano Luperini em seu livro Gli esordi del Novecento e l'esperienza della 'Voce'(1990), o empenho na produção das revistas comprovava que "os intelectuais ainda podiam ter uma função na sociedade da produção em massa" (p. 10).

Revistas como La Voce e Leonardo tiveram uma grande importância nas primeiras décadas do século até o advento do fascismo, que coibiu a livre expressão, fazendo que poucas edições sobrevivessem ao período da ditadura, como é o caso da famosa La critica, revista de crítica literária fundada por Benedetto Croce que durou quarenta e dois anos (de 1903 a 1944).

Com o final da guerra, o papel do intelectual na sociedade tornou-se assunto central em toda Europa; surgiram diversas publicações com o intuito de discutir questões relacionadas à cultura de massa, ensejando o debate entre a classe operária e a classe intelectual. Emblemático o caso da revista Il Politecnico, fundada logo ao fim do conflito, em 1945, e dirigida por seu fundador, o escritor Elio Vittorini. Embora fosse filiado ao Partido Comunista Italiano, Vittorini propunha-se a manter nas páginas de sua revista um debate plural, aberto a intelectuais de várias extrações e voltado a contribuir para a construção de uma nova cultura democrática no país. Mas a tentativa de ingerência por parte do 
Partido, que desejava dar a própria orientação cultural para a publicação, acabou desaguando numa polêmica pública entre Vittorini e Palmiro Togliatti, então dirigente do PCI. Essa polêmica acabaria custando a vida da revista, que tinha no Partido Comunista seu maior patrocinador e divulgador. Esse caso mostra como, na verdade, a pluralidade do debate e a liberdade estavam, na prática, sujeitas a patrulhas ideológicas desejosas de construir uma cultura nacional, pretensamente baseada nos moldes apontados por Gramsci, em seus escritos.

Vale lembrar que, nos anos cinquenta, a Itália, livre da ditadura fascista e dos horrores da guerra, vivia um momento de grande otimismo social motivado pelo crescimento industrial, pelos meios de comunicação de massa e pela melhoria de qualidade de vida que, de forma geral, se instalara naquele país que tanto sofrera durante a Segunda Grande Guerra. Nesse clima de otimismo e consolidação de ideais partidários, eram poucos aqueles que procuravam tecer uma análise dos fatos livres de amarras ideológicas rígidas.

Na contramão do engajamento político-partidário, temos a publicação de Tempo Presente: informazione e discussione, revista fundada em 1956, como uma das vozes da Associação Europeia pela Liberdade da Cultura que tinha em Silone uma das principais figuras, em nível europeu.

A maioria dos colaboradores de Tempo Presente partilhava ideais socialistas, entretanto a revista caracterizou-se por permitir questionamentos sobre os caminhos da política e da sociedade italiana e mundial, fato que desagradava os ativistas partidários e pretensos reconstrutores da nação italiana. Apesar disso, Tempo Presente: informazione e discussione foi publicada por 12 anos (entre abril de 1956 e dezembro de 1968) sob a direção de Ignazio Silone e Nicola Chiaromonte, com a contribuição de intelectuais de vários países.

Para esclarecer a importância de se ter Silone e Chiaromonte na direção da 
revista, farei um breve relato sobre esses autores. Ignazio Silone, nascido em Pescina dei Marsi em 1 de maio de 1900, com o nome de Secondino Tranquilli, foi fundador do Partido Comunista Italiano ao lado de Gramsci e Togliatti, mas foi desligado do Partido em 1931, por se recusar a seguir as ordens de Moscou sob a direção de Stalin. Tranquilli, então refugiado na Suíça, assumiu definitivamente o pseudônimo de Ignazio Silone e tornou-se um dos escritores mais conhecidos daquele período, especialmente pela publicação, em 1933, na versão alemã, de seu primeiro romance, Fontamara. Ao término da guerra, em outubro de 1944, o autor retornou a Itália e reiniciou sua carreira política, agora no Partido Socialista, mas os caminhos da política italiana o fizeram ver que sua luta pelas melhorias sociais deveria seguir outro rumo e, a partir daí, desligouse da política partidária e tornou-se um "socialista sem partido e um cristão sem igreja”. Ignorado como autor em seu país, Silone continuou a gozar de prestígio internacional, especialmente por sua atividade na Associação pela Liberdade da Cultura, entidade europeia nascida ao término do conflito mundial. Silone foi narrador, ensaísta e jornalista, tendo sua atividade sempre voltada para dar voz aos oprimidos e em defesa da justiça; sua principal proposta era a de “entender o papel do homem na engrenagem do mundo moderno". O autor faleceu na Suíça em 1978 e sua figura foi rapidamente esquecida até que, no fim dos anos 90, dois historiadores, Dario Biocca e Mauro Canali, surgiram com "provas", ao que parece inquestionáveis, de que Silone teria sido um espião fascista. Desde então, a polêmica provocou inúmeras publicações, quase todas em defesa do autor e novas pesquisas sobre as atividades de Silone dentro e fora do Partido Comunista. Alguns pesquisadores foram mais recentemente a Rússia para pesquisar as atividades de Silone e a Rivista Panorama (18/08/2011) traz a notícia de que teriam sido encontradas cartas que comprovam que a relação entre 
Silone e o comissário fascista Guido Bellone se devia a ordens diretas de Moscou (as supostas cartas seriam assinadas por Lenin e, posteriormente, por Stalin), e ele seria, desse modo, um infiltrado comunista. Outro fato importante é que esse pesquisador teria encontrado um manuscrito de Fontamara anterior a 1930.

Nicola Chiarmonte, crítico e ensaísta pouco conhecido hoje na Itália e no exterior, começa a ter sua produção revista pelos intelectuais neste momento. Nascido em Rapollo na Lucania (atual Basilicata), em 1905, atuou na juventude no grupo Giustizia e libertà, mas acabou refugiando-se na França, para fugir às perseguições fascistas, e lutou na guerra da Espanha sob o comando de André Malraux. Abandonou a luta por não concordar com as ideias do comunismo de Stalin. Contrário a todas as ditaduras, passou a ser perseguido e refugiou-se em Paris, na Argélia, no Marrocos e, finalmente, em Nova York, onde viveu entre 1944 e 1947 e esteve em contato com o grupo dos refugiados de Gaetano Salvemini, por meio do qual se tornou amigo de intelectuais locais, como Mary Mcarthy, Dwight Macdonald, Hanna Arendt, Irving Howe e outros que contribuiriam, anos mais tarde, com artigos para Tempo Presente. Em 1947, em Paris, conheceu Albert Camus, que se tornou um grande amigo. A partir de 1951, estabeleceu-se em Roma como articulista do jornal Il mondo e viveu ali até sua morte, mas, como observa Giovanni Russo em seu artigo "Nicola Chiaromonte un maestro segreto" (Corriere della Sera, 22/12/1999, p. 37), "parecia desentrosado no ambiente romano como se sentisse ainda o desconforto do exílio". Na direção de Tempo presente, Chiaromonte escreveu sobre Moravia (outro grande amigo), Pasternak, Camus, Tolstoi, Stendhal, Sartre e tantos outros e foi, ainda, um grande crítico de teatro e cinema. Seus escritos estão reunidos em diversos livros, sendo os mais famosos Scritti sul teatro, Il tempo della malafede e Credere e non credere. O crítico morreu em 1972, aos 66 anos. 
Assim como Silone, Chiaromonte foi um dos poucos intelectuais italianos que viveram experiências internacionais e tentaram ampliar a visão dos italianos para a literatura e para as questões político-sociais mundiais; talvez por isso eles tenham sido autores pouco compreendidos, esquecidos por muitos anos após a morte e definidos como "estrangeiros na pátria"

No texto que abre o volume comemorativo sobre Tempo Presente, intitulado "L'importanza di una rivista", Gustaw Herling, um antigo colaborador, observa:

Tempo Presente ha avuto l'enorme merito di contribuire a rompere certi schemi e a superare vecchie convenzioni teoriche e politiche molto diffuse. Già nel primo numero della rivista, Silone propose uma distinzione decisiva tra “ideologie e realtà sociale”. Per lui la realtà sociale era molto importante, e andava costantemente studiata, pensata, esaminata. Le ideologie gli sembravano invece pericolose. Per lui rappresentavano la radice, la fonte autentica di tutti gli assassinii di massa, di tutti gli orrori che pesavano sulle vicende dell" Europa. Non solo l'ideologia comunista: tutte le ideologie. (p.15).

Herling conclui que a revista se tornou "importante e influente" no âmbito internacional, sem se deixar contaminar pelo provincianismo de certa crítica italiana, e que procurou, com sua filosofia, "recuperar a importância e dignidade da figura do 'intelectual' que estava desgastada após a Segunda Guerra” (p.15).

Pelas notícias sobre esses intelectuais pode-se inferir a qualidade dos textos que se encontram em Tempo Presente. Na apresentação da revista, no número inicial de abril de 1956, o editorial esclarece a motivação cultural da publicação: 
La nostra vuol essere una rivista internazionale. Con questo intendiamo un'impresa culturale fondata sulla constatazione che il mondo d'oggi non ha più confini. Questo non perché quelli politici e etnici siano aboliti, ma perché sono incerti e problematici i confini del nostro mondo morale. Incerte le norme del comportamento individuale; incerti il significato e i limiti dell'azione politica quale oggi la si pratica o la si propugna; incerto soprattutto il valore delle idee e ideologie correnti.

Tale incertezza non è motivo di scetiscismo. ̇̀ semplicimente il fatto fondamentale del nostro tempo, indubitabile, essenzialmente presente e sentito dovunque....

Sarebbe difficile, oggi, dire dove siano la metropoli, la capitale, il centro. Noi vediamo, nel mondo, formidabili centri di potere economico, tecnologico e politico; ma non vediamo ancora l'essenziale, ossia un centro di prestigio intellettuale e morale indiscusso e valido per tutti. In attesa, è legittimo dire che il centro, per ora, è là dove la coscienza del vero si manifesta più libera ed energica.

Tempo presente preocupou-se essencialmente em tentar entender os caminhos dos sistemas de cultura (ou de sua crise) nos anos marcados pela guerra fria e pelo boom econômico que trazia consigo a ilusão das soluções dos problemas sociais.

Para concretizar sua proposta, a revista dividia-se em várias seções: agenda (geralmente sob os cuidados de Silone), artigos, contos, poesias, cartas de vários países (duas a cada número), discussão (sobre temas apresentados em 
números anteriores e sobre diversos argumentos da atualidade noticiados em outros jornais e revistas), gazeta (geralmente sob os cuidados de Chiaromonte, trazia comentários sobre livros, revistas, cinema, teatro e outras manifestações culturais) e, finalmente, uma parte dedicada a resenhas sobre as últimas publicações em língua italiana.

A revista testemunhou anos importantes do século $\mathrm{XX}$ e contou com a participação de intelectuais como Hanna Arendt, Isaiah Berlin, Gustav Herling, Albert Camus, Jorge Luis Borges, Dwight MacDonald, Octavio Paz, Theodor Adorno, Murilo Mendes, Boris Pasternak, Mary McCarthy, Arthur Koestler, Irving Howe, dentre outros autores de renome que contribuíram para oferecer sua visão do "tempo presente" por meio de artigos, poesias, contos e cartas, textos, enfim, intelectuais de diferentes partes do mundo que traçaram um quadro da realidade cultural, social, econômica e política daquele período.

Dentre os italianos podemos lembrar nomes de críticos e autores como Alberto Moravia (que já escreve sobre o romance no primeiro número da revista, a convite do amigo Chiaromonte), Olga Lombardi, Franco Lombardi, Alberto Arbasino, Enzo Forcella, Aldo Garosci, Andrea Caffi, Alfonso Gatto, Guido Guglielmi, Enzo Bettiza, Giorgio Agamben, Mario Perniola, Danilo Dolce, Leonardo Sciascia, Italo Calvino, Andrea Zanzotto, Tommaso Landolfi, Luce D’Eramo, Mario Tobino.

Um ponto que chamou a atenção durante a pesquisa foi o da discussão, no sentido de que os argumentos tratados não eram simplesmente deixados à recepção do leitor, mas eram propostos em diversos números com opiniões de diferentes colaboradores sobre o tema. A título de exemplo podemos citar um tema recorrente na revista: as opiniões sobre a perseguição soviética ao escritor Boris Pasternak, após a publicação de Dr Jivago; sua prisão, a proibição de ele 
aceitar o Prêmio Nobel, enfim, toda a experiência do autor oprimido pelo regime Comunista. Além disso, encontram-se poesias e contos inéditos do autor escritos para a revista e muitas leituras críticas de suas obras que foram apresentadas e discutidas durante anos, formando um precioso dossiê sobre o autor.

$\mathrm{Na}$ verdade, embora sejam discutidas várias questões sociopolíticas, Tempo presente dá ênfase sempre à literatura como força primordial que alimenta a "insaciável inquietude" e as fantasias humanas. Os críticos defendem, antes de tudo, a liberdade de expressão e de leitura, como elemento fundamental para a contínua formação e transformação do sistema de cultura. No texto "Nichilisti e idolatri: dopo il neorealismo", publicado no número de setembro-outubro de 1963, Silone conclui seu texto sobre as novas tendências literárias afirmando:

Il posto dell'arte e della letteratura nella vita sociale non può essere stabilito da alcuna legge o consuetudine. $\grave{E}$ questo che fa di esse il simbolo stesso della libertà. Ma vi sono due maniere di perdere la libertà: nel soprirmene le condizioni e nel non servirsene. La sola via efficace per uno scrittore, di evitare $i$ vicoli ciechi, del nichilismo e della idolatria politica, è in un continuo sforzo di ricerca e di libera creazione. La fuga non salva nessuno, pure se nessuno può essere obbligato ad occuparsi dei problemi della propria epoca. In una Città libera, a mio parere, dev'esserci posto anche per la Torre d'avorio. (p.8).

A tônica da revista, de fato, recairá sempre sobre a liberdade de expressão cultural e de seus significados na construção da sociedade presente e futura. Mais do que isso, a liberdade de expressão é vista como ato comunicativo essencial na 
construção do "tempo presente", com vistas ao futuro, como pode se comprovar na leitura dos textos de Chiaromonte que, no artigo "Tra silenzio e parola", de agosto de 1962, aborda a questão da presença do homem no presente e além dele, pois comunicar é "um ato de confiança em nós mesmos, nos outros, no mundo, na essência última das coisas..." (1962, p. 570, tradução nossa).

C'è di più. Se non è intriso di volontà di dominio, e da questa falsificato, l'atto di comunicare implica la credenza, oltre il presente, nel futuro e, oltre il futuro, in ciò che dura e permane. Questo dunque importa, e non la reazione fugace all'impressione fugace. E questo implica abnegazione dell'individuo di fronte ai suoi simili presenti e avvenire: abnegazione di fronte all'esistenza comune non oggi soltanto, né domani, ma per un tempo indefinito... tale abnegazione non può che esser fondata che sulla fiducia in ciò che dura, fiducia che fa tutt'uno con l'aspirazione a sormontare l'effimero. Né questa aspirazione si può distinguere dalla fede nella permanenza di ciò che è vero e buono. La quale fede è, alla fine, fondamento e fondazione dell'atto di comunicare. Sicché bisognerebbe concludere che parlare agli altri è sempre un parlare in vista dell'eternità. (CHIAROMONTE, 1962, p. 570)

A comunicação, como ato em relação ao outro e como negação do niilismo, é uma marca constante dos escritos dos colaboradores de Tempo presente.

Ao final do período de pesquisa descobri que a revista Tempo presente retomou suas publicações a partir de fevereiro de 1980, sob a direção do Prof. 
Dr. Angelo Sabatini, titular aposentado de Filosofia da Università degli Studi "La Sapienza" di Roma. A retomada das publicações de Tempo presente, explica o professor Sabatini no editorial do primeiro número de 1980, “deve ser entendida como referência a um modelo de projeto cultural e a um modo exemplar de fazer cultura no momento presente" (tempopresenterivista.eu)

Apresento, a seguir, a tradução integral do texto "Tra silenzio e parola", publicado na revista em agosto de 1962.

\section{Referências Bibliográficas}

CHIAROMONTE, N.; SILONE, I. Tempo Presente: informazione e discussione. Roma, 1956-1968.

LUPERINI, R. Gli esordi del Novecento e l'esperienza della “Voce”. Bari: Laterza, 1990.

HERLING, G. L'importanza di una rivista. In: FOFI, G.; GIACOPINI, V.; NONNO, M. (Orgs.). L'eredità di Tempo Presente. Roma: Fahrenheit 451, 2000. 


\section{Tempo Presente, outubro i962 Entre o SILÊNCIO E a PALAVRA}

Nicola Chiaromonte

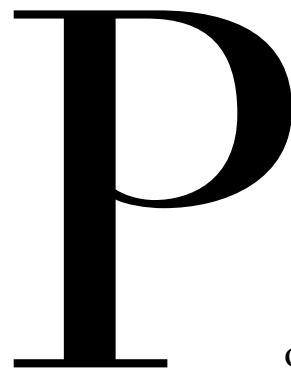

or que falar ao invés de calar? Por que escrever? É uma pergunta que já fazia a Mallarmé le vide papier que la blancheur défend e parece que se possa responder de três modos .

O primeiro é o do próprio Mallarmé, já vislumbrado por Flaubert e Baudelaire, segundo o qual a arte começa depois que cai sobre cada coisa (e especialmente sobre o ego do próprio artista) o véu da resignação muda e encontra-se, face a face, na solidão e no silêncio, um Eu desencarnado e o 
Nada. Quando começa a falar, o poeta já superou a inutilidade de cada palavra para os fins mundanos: a poesia não é expressão, mas nulificação dos objetos do mundo, palavra pura que se recusa a nomear e pretende fazer existir da realidade precisamente aquilo que está ausente dela.

A arte é, aqui, um princípio ético e seu culto é fundado na perda de toda esperança quanto ao significado deste mundo e à existência de qualquer outro espaço ou céu, no qual tal ausência de significado possa ser compensada: a idealidade - l'azur - de Mallarmé é um vazio consciente do seu nada. Poetar é suportar o peso do mundo transcendendo-o na direção de um significado impossível, aliás, absurdo. Nesse sentido, o poeta do Coup de dés pode ser considerado o precursor do existencialismo ateu.É importante notar, porém, que a resposta de Mallarmé não é uma evasão da realidade, mas uma forma extrema de estoicismo fundada sobre um julgamento radical quanto ao significado do mundo.

Quantos são hoje os artistas que permanecem fiéis a uma moral tão austera? Pouquíssimos. A maioria para na segunda resposta, a menos difícil, segundo a qual o artista é um produtor de objetos de qualidade especialíssima oferecidos ao gozo de quem os sabe apreciar. Ao artista cabe produzir esses objetos e não perguntar qual sua necessidade: a única necessidade válida é a que o leva a fabricá-los do modo como o faz, a necessidade interna da arte.

Nesse caso, a questão da relação entre a arte e o mundo não se coloca de maneira alguma, assim como não se coloca a questão do significado do mundo, o qual é considerado como uma ocasião para a arte, uma fonte de temas ou pretextos. Note-se, todavia, que, nesse contexto, perguntar que sentido tem o mundo é irrelevante, e também é irrelevante a pergunta sobre o significado da arte: ele poderia ser infinito ou igual a zero. Além disso, enquanto a resposta de 
Mallarmé vale somente para a arte pura, separada dos significados ordinários e da universel reportage, essa segunda pode valer para qualquer espécie de arte: pura ou impura, realista ou abstrata, de vanguarda ou tradicional. Da mesma forma, salvo um escrúpulo mais ou menos grande pela dignidade formal, a uma arte compreendida desse modo pode convir qualquer tipo de mundo, incluídos aqueles em que a arte é um negócio de Estado ou uma mercadoria.

A terceira resposta, finalmente, é aquela do artista que, para atuar, precisa - como qualquer outro indivíduo - de uma razão, ou seja, precisa estar convencido do significado daquilo que faz e, em particular, precisa conhecer a relação entre o objeto que ele fabrica e o mundo para o qual o faz. É uma situação que pode ser compartilhada pelo antiquíssimo ceramista de Kamares e Tolstói: o que a distingue é a necessidade (ou a busca) de uma razão suficiente, o reconhecimento da ligação entre o artista e o mundo dos outros, a ausência de presunção demiúrgica.

É a resposta do senso comum. E, no fundo, é também aquela de todo verdadeiro artista, qualquer que seja sua teoria da arte ou o tipo de arte que pratique. Mas, para um artista de hoje, ela é também a mais problemática. $\mathrm{O}$ artista que hoje se interrogue sobre a necessidade e o significado de seu fazer artístico, como já fazia Tolstói, está dizendo, em primeiro lugar, que está insatisfeito com os outros dois tipos de resposta que, pela lógica, são efetivamente especiosos; e, em segundo, que ele tem consciência de uma situação crítica da arte no mundo atual, da qual não se sai com a simples afirmação da liberdade demiúrgica do artista. Mas, exatamente porque tem consciência da crise, ele sabe também que o simples retorno ao senso comum ou ao "realismo", a busca de uma verdade encarnada para oferecer, a inserção nas chamadas circunstâncias "históricas" são trivialidades. Recorrer ao senso comum nada mais significa do que um 
retorno aos dados elementares do problema. Ora, os dados elementares do problema não remetem à arte, mas à situação atual do indivíduo, à realidade presente do mundo e à consciência que dela se pode ter.

"Sobre aquilo de que não se pode falar, é preciso calar-se", dizia Wittgenstein. É possível calar-se, e essa decisão também significará alguma coisa. A arte moderna, sob certos aspectos, é uma forma do silêncio mais do que da palavra. Mas, se alguém fala, é porque quer dizer aos outros a própria opinião sobre aquele fato comum que é o mundo. Isso implica já, de saída, o reconhecimento preliminar dos outros como eles são e do mundo como ele é; sem isso, o impulso de comunicar seria infundado e inexplicável.

A rigor, na nossa vida, quando estamos acordados nunca nos calamos: falamos entre nós; ou seja, em nós, a parte de nós que diz "eu" dirige-se ao "outro" - o desconhecido que escuta e não diz nada - para obter anuência, e a linguagem que os dois falam nada mais é do que a linguagem de todos. O próprio trabalho do pensamento, o esforço que fazemos (ou melhor, a que somos submetidos) para desemaranhar da desordem um pensamento claro pode bem ser aquilo que Robert Musil chama "um estado realmente lamentável, uma espécie de cólica de todos aos giros do cérebro", isto é, um processo obscuro e totalmente privado. Mas, como diz o próprio Musil, assim que formulamos um pensamento distinto, ele "já perdeu a forma do pensar... para tomar a forma da coisa pensada; e essa forma, infelizmente, é impessoal, porque o pensamento é, então, voltado para o exterior, destinado à comunicação". Isto é, a "coisa pensada" não só pertence ao mundo, mas já pertencia a ele desde o princípio, desde o impulso e a angústia que provocaram seu nascimento. De propriamente nosso, em nós, há apenas o modo como surgem e se sucedem os pensamentos e os estados de alma; mas pensamentos e estados de alma dizem respeito sempre 
ao mundo e, assim que são nomeados, já são dirigidos aos outros. Ou, como diz Husserl, "cada consciência é sempre consciência de alguma coisa".

Por isso, na origem, falar é alienar-se, despersonalizar-se, jogar-se no mundo para participar da vida do mundo e criar, no meio dos outros, uma imagem sólida de si: uma "pessoa" (no sentido latino de "máscara") porque nós gostaríamos de manifestar totalmente nós mesmos, mas aquele nosso ser íntimo e privado, aquela parte de nós que nenhum de nossos movimentos e discursos conseguem exaurir nunca, não pode ser nada além da matéria prima, ou por assim dizer, o alimento. A pessoa que procuramos ser, devemos escavála na matéria mais dura entre todas que é a linguagem comum, aquele estado presente das palavras, dos sinais e de sua sintaxe, ao qual, do ponto de vista da comunicação se reduz o que chamamos de "mundo".

Essa é uma matéria que, pela sua natureza, não nos pertence e nunca poderá nos pertencer exclusivamente: legado e propriedade de todos, de ninguém e de cada um. O máximo que podemos fazer é acentuá-la da nossa maneira, extrair dela figuras mais ou menos efêmeras: à nossa imagem, se quisermos, mas sempre em função dos outros, para participar aos outros o nosso modo de sofrer e entender o mundo. Por mais que seja nossa no acento, a imagem será sempre uma imagem do mundo comum, extraída da linguagem comum, e fique claro que "mundo comum" aqui não significa o mundo dos objetos exteriores, das situações materiais ou sociais, da vida cotidiana ou da política; é tudo isso mais aquela realidade indeterminável que é o modo como cada um de nós pensa, entende e sofre o mundo dito "exterior" e as relações com os outros. Aquilo que conseguiremos transmitir de nós próprios no nosso discurso dependerá do estado da linguagem comum e de sua sintaxe, isto é, do estado real do mundo, de sua ordem ou desordem relativa.Se isso é verdade na comunicação 
ordinária, é mais verdade ainda na comunicação da segunda potência que é o discurso da cultura. A ordem da cultura é aquela em que o individuo ambiciona existir de maneira eminente e deixar uma mais autêntica memória de si; mas é também aquela em que, para obter isso, o indivíduo deve saber abandonar-se mais generosamente à experiência do mundo e à vida da linguagem.

No relacionamento habitual com os outros, nos perdemos e nos encontramos a cada passo, ou acreditamos nos encontrar, às vezes, sobrepujados pelas razões e palavras dos outros, às vezes, ao contrário, fortalecidos pela consciência de nós próprios e das nossas razões, reveladas a nós mesmos graças ao confronto com os outros. Mas quando queremos falar com a finalidade precípua de dizer algo que tenha forma, verdade e consequência, nos arriscamos para fora de nós próprios somente com o suporte de uma linguagem que não nos pertence e de um mundo do qual somos uma parte ínfima; assim que formulamos nosso primeiro pensamento, somos tomados pela necessidade de uma lógica que nem sequer é nossa, mas do discurso. Perdemo-nos no labirinto de significados possíveis, sem nenhuma certeza de encontrar nem nós nem o mundo. Isso na ilusão de obter o quê? O que nos parece um acento correto em um grupo de palavras, uma relação justa entre significados, um discurso coerente, em um mundo em que nos com os nossos acentos, os nossos significados, as nossas reflexões permaneceremos sempre uma parte infinitesimal. Para obter isso, teríamos que nos reduzir somente àquela pequena parte de nós que era capaz de produzir a talvez preciosa, mas, de qualquer forma, mínima modificação de um legado comum, submetido ele próprio aos golpes do destino, à decomposição e ao esquecimento.

"The end is dispair" conclui Shakespeare pela boca de Próspero. O fato é que o homem quer responder ao menos com a palavra aos "golpes dos Deuses 
de ombros grandes". Todavia, se insiste em fazê-lo, não se pode pensar que o faça para si, nem pela ilusão de mudar o mundo com as palavras: por isso, deve sentir a necessidade da presença dos outros, deve estar direcionado para os outros, desejoso de ser alguém, um em meio aos outros.

Falar, portanto, é um risco que é medido pela desproporção entre o peso da linguagem comum - na qual gravita por inteiro o peso da realidade - e a voz do indivíduo. Se há um compromisso ao qual o artista não pode se subtrair, é aquele em que se encontra preso desde o início de seu discurso e é, antes de tudo, um estar envolvido e preso no mundo da palavra. Traduzir esse compromisso em fórmulas imperativas é um absurdo, uma vez que é com toda a estrutura do próprio ser moral que cada um de nós está envolvido no mundocomo os outros, isto é, cada um de nós junto com todos os outros, fizeram e fazem. Mas os limites dos riscos são evidentes: de um lado a banalidade, de outro a insensatez. A primeira regra é que não há regra para se evitar nem uma nem outra; a segunda, que o significado das palavras não depende de quem as usa, mas do mundo ao qual elas pertencem, ao qual são destinadas e para cuja órbita retornam assim que são pronunciadas.

Não se foge às consequências das próprias palavras assim como não se foge às consequências dos próprios atos; aliás, foge-se muito menos das consequências das palavras, já que a necessidade que rege as palavras, sendo ela pura e assumida livremente, é bem mais clara do que aquela dos atos. Podemos nos servir das palavras para confundir o significado dos atos, mas confundir o significado das palavras não é possível: podemos somente fazer discursos confusos.

Portanto, o que protege os nossos discursos da dissolução e os salva da insignificância não é a intenção que colocamos nas palavras, mas a ordem 
do discurso que conseguimos construir, a maior ou menor clareza com que expressamos no discurso a razão pela qual falamos. E ainda, por mais poético que pretenda ser nosso discurso, essa razão nunca poderá ser apenas pura sensibilidade, puramente subjetiva: ela vai se referir sempre ao horizonte dos significados, ao mundo comum, à realidade física e moral de que è parte quem fala junto com todos aqueles aos quais se dirige.

Isso já desmente a pretensão do artista contemporâneo de poder se servir das palavras e dos signos em um sentido totalmente particular, desmembrandoos e recolocando os fragmentos segundo seu arbítrio, ou até por acaso. O que se tenta, agindo assim, é encontrar um ponto que esteja a distância infinita da linguagem comum, de onde o artista possa se servir das palavras e dos signos em toda pureza e objetividade, para construir significados que tenham com o mundo uma relação puramente alusiva. Ora, isso só seria possível se existisse para a arte a possibilidade que existe para a matemática de proceder por símbolos exatos que não têm outro significado fora do seu âmbito. Mas, de fato, não há palavra, signo, combinação de sinais ou de palavras que não sejam permeados de significados mundanos e que, qualquer que seja o modo em que forem usados, não evoquem os objetos aos quais, em última instância, se refere. Por mais que queira se afastar da linguagem comum, o artista nunca pode sair do mundo para atingir o reino dos símbolos, dos quais ele possa se dizer dono e árbitro: a justificação dessa liberdade está justamente na dependência do mundo e dos outros em virtude da qual a arte nunca pode se tornar um modo de organizar e manipular os objetos do mundo para obter efeitos inauditos - uma técnica - mas, mesmo quando sua linguagem é mais rarefeita e preciosa, permanece uma maneira de interpretar a experiência e de dar forma a um conteúdo que ela própria assume como pré-existente. Por mais que procure evitar a gramática 
da experiência ordinária, a arte não pode nunca se desvencilhar das suas leis: pode somente fechar-se num jogo mais ou menos sutil de alusões. Mas o esforço de significar alguma coisa indo contra a linguagem das aparências, isto é, abstraindo-se da existência - além dos equívocos, das mistificações e das inércias - de um mundo comum irremovível, fundado na condição comum dos homens tanto quanto na natureza e na vida associada, conduz a um beco sem saída.

Aquilo que, na realidade, o artista moderno pretende com sua tentativa de "abstrair" toda forma naturalmente dada ou preconcebida é fugir da corrupção da linguagem convencional. O beco sem saída em que ele vai desembocar, por um lado, é o resultado da própria condição do mundo humano, por outro, é a consequência lógica da ideia que o artista formou sobre a arte no curso do século XIX, ideia que faz do artista o senhor e árbitro absoluto da linguagem de que se serve. Está em ação, aqui, algo semelhante a uma fatalidade. Mas, por isso mesmo, seria necessário reconhecer a situação por aquilo que ela é, uma fase crítica, contraditória e problemática da arte assim como da condição humana, e não falar dela como se tratasse simplesmente de uma nova forma da sensibilidade.

Culpar o artista pelo gênero de arte que ele persegue - do "estilo" ao qual ele se conforma - é absurdo, visto que precisamente o estilo não é algo que se possa criar arbitrariarmente, mas é determinado pela condição da linguagem naquele momento particular, portanto, por uma situação objetiva, e nunca pode ser uma invenção individual. Se o artista é culpado, a sua não pode ser senão uma culpa comum a ele e a nós, seus contemporâneos: uma consciência escassa do mundo em que vivemos, isto é, da ligação que nos une aos nossos semelhantes e nos submete a um destino comum. A arte é a tentativa 
de dar forma e palavra a esse destino e não pode ser nada além disso. Uma arte disforme só espelha a realidade de uma consciência desordenada, incapaz de dominar as ocasiões: condená-la porque não obtém uma forma clara não tem sentido, uma vez que essa forma não poderia ser senão aquela de um mundo inexistente. Mas não menos absurdo é querer que o disforme seja uma nova espécie de forma, o ir ao acaso uma espécie de ordem e que, enfim, certos aspectos da arte contemporânea representem outra coisa que não os modos da negação e da recusa, tentativas extremas e extremamente ambíguas de significar algo sem comunicar nada.

O que é certo, em todo caso, é que nenhum homem, artista ou não, pode ser superior ao mundo do qual faz parte, à trama de relações à qual está preso, a uma situação de consciência na qual ele nunca pode estar sozinho, mas nem que seja apenas na forma de linguagem - encontra sempre a sua relação com os outros, a dependência decada tem um de todos os outros, o enigma da "natureza humana" e, no fundo dessa dependência e desse enigma, aquele fato preponderante que os antigos chamavam o Ser: a presença de todas as coisas juntas, em toda sua luz e em toda sua escuridão.

Se falamos, , portanto, dessas realidades que falamos, confiando nossas palavras à consciência dos outros com um ato que é, de qualquer modo, um ato de confiança em nós mesmos, nos outros, no mundo e no ser último das coisas.

E há mais. Se não for permeado de vontade de domínio e se não for por ela falsificado, o ato de comunicar implica a crença, além do presente, no futuro e no que dura e permanece. É isso que importa e não a reação fugaz à impressão fugaz. E isso implica abnegação do indivíduo diante de seus semelhantes presentes e futuros: abnegação diante da existência comum não somente hoje nem somente amanhã, mas por um tempo indefinido, até quando existirá o 
mundo, até o fim dos tempos. Essa abnegação, por sua vez, só pode estar fundada na confiança naquilo que dura, confiança que coincide com a aspiração de superar o efêmero. Essa aspiração tampouco pode ser separada da fé na permanência daquilo que é verdadeiro e bom. Essa fé é, enfim, fundamento e fundação do ato de comunicar. De modo que se deveria concluir que falar aos outros é sempre falar tendo em vista a eternidade.

Tradução de Doris Natia Cavallari Revisão: Letizia Zini Antunes 